\title{
O MÉTODO DO CASO NO ENSINO JURÍDICO COMO RESPOSTA À NECESSÁRIA ABERTURA DOS TEXTOS NORMATIVOS SOBRE RESPONSABILIDADE CIVIL
}

\section{CASE METHOD IN LEGAL EDUCATION AS A RESPONSE TO THE NECESSARY OPENNESS OF NORMATIVE TEXTS ON TORT}

\section{LIABILITY}

\begin{abstract}
ANTONIO JORGE PEREIRA JÚNIOR
Doutor, Mestre e Bacharel em Direito pela Faculdade de Direito da Universidade de São Paulo (USP). Professor do Programa de Mestrado e Doutorado em Direito da Universidade de Fortaleza (PPGD - UNIFOR). E-mail: antoniojorge2000@gmail.com.

\section{MÁRCIO ANDERSON SILVEIRA CAPISTRANO}

Mestrando no Programa de Mestrado e Doutorado em Direito da Universidade de Fortaleza (PPGD - UNIFOR). Pesquisador bolsista da Fundação Cearense de Apoio ao Desenvolvimento Científico e Tecnológico (FUNCAP). Advogado da União. E-mail: marcioandersonsc@gmail.com.
\end{abstract}

\section{RESUMO}

O presente artigo objetiva verificar a utilidade e a forma de aplicação do método do caso (case method) no ensino jurídico da responsabilidade civil. Trata-se de ramo marcadamente jurisprudencial, com textos normativos abertos e imprecisos. A partir da pesquisa bibliográfica, constata-se que o método do caso propicia o indispensável desenvolvimento da razão prática jurídica, empregada na atividade interpretativa voltada à decisão considerada justa para o caso concreto. Tal método prepara a capacidade reflexiva para percepção dos valores e interesses envolvidos no caso submetido a análise, mais necessária em face da insuficiência do direito legislado e 
da doutrina. Em perspectiva pragmática, o artigo traz indagações exemplificativas aptas a estimular a reflexão do discente em matéria de responsabilidade civil. Apresenta-se, ainda, roteiro ilustrativo de aula a respeito de um problema jurídico real: a possível responsabilidade do Estado por nomeação tardia em concurso público, tema enfrentado pelo STF no julgamento do Recurso Extraordinário n. 724.347/DF, em regime de repercussão geral.

PALAVRAS-CHAVE: Método Do Caso; Responsabilidade Civil; Ensino Jurídico; Didática; Razão Prática Jurídica.

\section{ABSTRACT}

The present article aims to verify the feasibility and the means of applying the case method in legal education of tort liability. It is a niche markedly jurisprudential, with open and imprecise normative texts. Through bibliographical research, it is verified that the case method propitiates the indispensable development of juridical practical reason, used in the interpretive activity focused on the decision considered just for the concrete case. This method prepares the reflective capacity for understanding of the values and interests involved in the case submitted for consideration, which is more necessary in view of the insufficiency of statute law and doctrine. In a pragmatic perspective, this article lists exemplary questions capable of stimulating student's reflection on tort liability. It also presents an illustrative lesson plan on a real juridical problem: possible State liability for late nomination in civil service examinations, a matter faced by Supreme Court in the judgment of Extraordinary Appeal no. $724,347 / D F$, under the system of general repercussion.

KEYWORDS: Case Method; Tort Liability; Legal Education; Didactics; Juridical Practical Reason. 


\section{INTRODUÇÃO}

Desde o início do século $\mathrm{XX}$, tem havido uma crescente expansão das situações tratadas sob a incidência da responsabilidade civil, de modo a alargar as fronteiras do instituto. Por essa razão, proporcionalmente, aumentou a insegurança interpretativa diante da dificuldade de o legislador lidar com tão acentuado desenvolvimento, em razão da impossibilidade de antever com maior precisão as diversas espécies de conflitos. O direito da responsabilidade civil apresenta a característica de ter uma disciplina legal concisa, a ensejar maior margem interpretativa na concretização do direito.

Nesse contexto, que parte de textos normativos abertos ou com maior grau de insuficiência, a composição do direito da responsabilidade civil é marcadamente dinâmica, e se apoia sobremaneira na construção jurisprudencial, que por sua vez envolve a atuação de advocacia e da doutrina durante o processo de construção da decisão judicial.

Ainda, em matéria de responsabilidade civil, é frequente a constatação de que o conjunto de textos normativos do ordenamento jurídico se mostra em descompasso com os desafios da contemporaneidade. Deste modo, assume maior relevo a necessidade de prudente apreciação dos fatos e do direito por parte do intérpreteaplicador do direito, sempre atento aos valores entremostrados na Constituição e atuando em consonância com as transformações sociais.

Diante desse quadro, potencializa-se o desafio da educação jurídica na disciplina de responsabilidade civil. A mera exposição do conteúdo de textos normativos, já insatisfatória em outros âmbitos jurídicos, revela-se ainda mais deficitária na missão de enfrentar em sala de aula os meandros do direito dos danos.

O presente artigo, por meio da pesquisa bibliográfica, busca verificar a viabilidade, a utilidade e a forma de aplicação do método do caso (case method) como forma de desenvolver a razão prática do discente a partir do estímulo à construção da resolução de problemas jurídicos envolvendo a temática da responsabilidade civil. 


\section{DIREITO E REALIDADE: O DIREITO LEGISLADO COMO MERO PONTO DE PARTIDA DA INTERPRETAÇÃO JURÍDICA}

Para a compreensão da norma jurídica na hermenêutica jurídica contemporânea, mostram-se úteis também as lições de Friedrich Müller (2009, p. 192231), as quais se apresentam como contraponto direto ao positivismo jurídico, especialmente à teoria de Hans Kelsen. Segundo Müller, o texto normativo não é uma expressão qualquer a ser conhecida pelo jurista, mas uma formulação linguística que implica um grau de normatividade que orienta a resolução de problemas concretos. Desse modo, a atividade do jurista se volta ao conhecimento e à fixação de sentidos diante não apenas do texto normativo, mas, sobretudo, diante do caso concreto para o qual o texto se orienta. Para Müller, a norma jurídica se compõe a partir de elementos linguísticos em torno do texto (programa da norma) e dos dados reais do caso concreto (âmbito da norma). Em outras palavras, o programa da norma é a disposição da norma, ou seja, o objetivo que a norma do caso concreto pretende alcançar, enquanto o âmbito normativo é o rol de situações concretas que a norma pretende controlar. É a partir da junção de ambos que se chega ao terceiro e último ponto do processo interpretativo proposto por Müller: a norma de decisão, distanciando-se a expressão textual da norma propriamente dita.

$\mathrm{Na}$ doutrina de Kelsen, existiriam normas jurídicas gerais, que gerariam molduras de significados possíveis, e normas individuais, obtidas por ato volitivo do julgador na escolha de um dos significados possíveis. Em contraposição, Müller (2009, p. 244-300) sustenta que a norma jurídica existe apenas para o caso particular e após construção pelo intérprete em um processo de concretização, de modo que não haveria norma jurídica previamente ao caso concreto. Assim, os legisladores não produziriam normas jurídicas, mas tão somente emitiriam textos normativos, que funcionariam como pontos de partida do processo de concretização. O teor literal de um texto normativo seria apenas a "ponta do iceberg" normativo.

Observa-se que, no pensamento de Müller, o significado do texto não é previamente dado, mas construído em situações históricas específicas, isto é, os sentidos só podem ser atribuídos em contextos específicos de realização. Ademais, 
em sede de responsabilidade civil, o texto normativo tem contribuição ainda mais embrionária, considerando que as disposições legais são sucintas e deixam amplíssima margem de decisão para a concretização do direito à indenização. Portanto, nesse campo jurídico, percebe-se com maior nitidez a imprescindibilidade da apreciação do âmbito da norma para a construção da norma de decisão.

Cabe trazer à baila também a compreensão de norma jurídica de Gustavo Zagrebelsky, o qual defende uma concepção de direito dúctil, maleável, flexível, no sentido de auto-adaptável às transformações da realidade, aproximando-se da ideia de âmbito normativo de Müller. Segundo Zagrebelsky (1995, p. 122), não é suficiente considerar o "direito dos livros", devendo-se perquirir o "direito em ação", de modo que é necessária uma "validade prática", para além de uma validade meramente lógica. O direito não é um dado, mas um constante "fazer-se", a partir da realidade viva das experiências sociais:

Resulta aquí oportuna la contraposición, cuyo profundo significado originario ya no se percibe hoy, entre scientia juris y juris prudentia, la primera como racionalidad formal, la segunda como racionalidad material, es decir, orientada a los contenidos. En términos aristotélicos, episteme frente a phronesis; en términos escolásticos, ratio especulativa frente a ratio pratica. Mientras el criterio que preside las primeras es la oposición cualitativa verdadero-falso, todo-nada, el que preside las segundas es una progresión cuantitativa que va desde lo menos a lo más apropiado, desde lo menos a lo más oportuno, desde lo menos a lo más adequado y productivo. Son dos mentalidades contrapuestas en general. En el lenguaje que hoy suele usarse, esta atención a lo posible en la realización de los principios se denomina $<<$ razonabilidad >> : una discutible expresión para aludir a lo que clásicamente se conocía como la <<prudencia >> en el tratamiento del derecho (1995, p. 123).

Prossegue o autor italiano afirmando que o direito deve ser tido como uma disciplina prática: "el caso no puede comprenderse jurídicamente si no es por referencia a la norma y ésta por referencia a aquél, pues no es sólo el caso que debe orientarse por la norma, sino también la norma la que debe orientarse al caso" (1995, p. 132). Assim, percebe-se a existência de vários métodos de interpretação não como um defeito teórico, mas como um dever da nossa cultura jurídica, de modo que a "razoabilidade" ou "prudência" deixa de se configurar como um elemento subjetivo do jurista para se objetivar no próprio ordenamento jurídico. 
Nessa esteira, a capacidade de relativização dos princípios jurídicos permite sua convivência em uma sociedade plural. Desse modo, os juízes seriam os guardiães da complexidade estrutural do direito, no marco da necessária e dúctil coexistência entre lei, direitos e justiça. Ademais, a pluralidade de princípios e de valores justificaria o tratamento não formalista ou não hierárquico dos fenômenos jurídicos, utilizando-se as ideias de prudência, ponderação, proporcionalidade e de otimização (ZAGREBELSKY, 1995, p. 125-126).

Por fim, a respeito do direito dos danos, Zagrebelsky (1995, p. 126) obtempera que a importância concedida aos valores na hermenêutica contemporânea não pode se distorcer a ponto de dar azo a um "mercado de valores", com a precificação de valores jurídicos por meio da expansão desenfreada do dano indenizável. A transformação dos valores lesados em valor-dinheiro significaria a submissão dos demais valores ao valor da economia, de modo que, numa sociedade pluralista, deve haver uma ponderação entre os valores envolvidos no caso concreto para obter-se a solução justa. Nitidamente mais complexo, portanto, o mister do docente de estimular a competência dos alunos de construir soluções jurídicas em casos de responsabilidade civil.

\section{A FUNÇÃO DA PRUDÊNCIA NA CONSTRUÇÃO DA SOLUÇÃO JURÍDICA: INFLUXOS NO ENSINO DO DIREITO}

Ciência e prudência são duas dimensões diferentes do saber humano: a ciência é um saber estritamente teórico, abstrato, especulativo, relativo ao universal e perene; a prudência, por sua vez, é prática, concreta, real e diz respeito ao singular e contingente. A prudência do direito ou jurisprudência, no sentido romano, era o conhecimento do direito e sua atuação pelo uso prático, buscando-se a justa solução para cada um dos casos concretos. O direito nasce e desenvolve-se em Roma como um saber prudencial, dado o perfil extremamente prático e pouco dado à abstração do povo romano (FERNANDES, 2014, p. 105-106). 
Na missão de construir o juízo prudencial de um caso concreto, tem lugar o labor hermenêutico, em que o hermeneuta constrói o sentido e o alcance de um esquema normativo, a fim de que, uma vez aplicado ao fato sob exame, busque-se uma solução concretamente justa. Desse modo, cabe ao jurista a criação da norma jurídica particular, dimensionando-a conforme a prudência.

O direito demanda uma atividade decisória e volitiva, campo de valoração das possíveis soluções judiciais para o caso, a culminar com a prolação daquela apta a produzir o justo concreto. Conhecer o direito, desta forma, é um saber prático (um conjunto de conhecimentos orientados não para o puro conhecer, porém, para o fazer), considerando as variações de cada caso concreto (FERNANDES, 2014, p. 109-110).

O juízo prudencial corresponde, desse modo, a uma concretização de natureza normativa, cuja finalidade, na seara jurídica, está em delimitar o justo concreto alcançável, porque, ao agir de acordo com o juízo prudencial, o jurista dá a cada um o que é devido.

A prudentia, que é reguladora de todo o comportamento digno do homem, apresenta-se, portanto, como virtude imprescindível à justiça (no sentido de dar a cada um o "seu"), ao permitir que o homem conheça e interprete objetivamente a realidade de cada coisa ou situação em relação ao todo e de acordo com suas finalidades. Define-se esta virtude como recta ratio agibilium (reta razão aplicada ao agir), habilidade da razão prática que leva o homem a priorizar, na tarefa avaliativa intelectual, o bem comum, em detrimento de interesses particulares que possam estar em conflito com aquele (AQUINO, 2005, p. 156-171). Essa concepção aproxima-se do ensinamento aristotélico de que a sensatez é a capacidade de agir com prudência (phronesis) e temperança (sofrosyne), o que acarreta tomar em consideração o bemestar geral (ARISTÓTELES, 2009, p. 132-134).

No texto normativo não está posto o direito. É da interpretação valorativa do texto que surgirá a norma jurídica. A justiça nascerá subjacente à decisão judicial na medida em que melhor atenda à solução do conflito em questão, levando em conta a estrutura altamente complexa da vida social e do ser humano (AMARAL, 2011, p. 206212). 
A jurisprudência também se reflete em um tipo especial de prudência, que é aquele aplicado à ciência do governo, sendo certo que a prestação jurisdicional é atividade intrínseca ao exercício do poder. Nesse diapasão, a proximidade da jurisprudência com a virtude da prudência é bastante visível e sua utilização pedagógica nitidamente relevante, considerando que a virtude se aprende pela educação e pela experiência.

Exsurge aqui a oportunidade para distinguir, de um lado, a atividade estatal de magistrado como exercício de poder e, de outro lado, o dever do jurista de definir o direito como exercício de prudência jurídica. Nesse sentir, emerge a necessidade de educar o jurista para compreender que a sustentação de uma posição ou decisão deve se dar a partir do argumento correto, adequado e justo, em vez da imposição voluntarista alicerçada no poder do Estado. A educação jurídica deve desenvolver a habilidade de percepção do justo pela atividade prudencial.

Afinal, educar não é apenas um saber teórico, mas, sobretudo, um saber prático, na medida em que se deve ensinar ao educando como agir. Essa afirmação é particularmente mais adequada no âmbito do ensino jurídico, a partir do fundamento de que a principal função do professor de direito deve ser desenvolver a razão práticojurídica dos alunos, isto é, sua competência para resolver problemas jurídicos.

No ensino jurídico, não deve haver a cisão entre razão teórica (ciência) e razão prática (juízo para a ação) que se observa cotidianamente, tendo em vista que esse dualismo não se repete na realidade profissional. Em sendo o direito um saber eminentemente prático, o cerne da estratégia pedagógica deve ser o estímulo à virtude da apreciação prudencial dos casos e o aperfeiçoamento de valores éticos, pois é certo que todo o conhecimento da realidade requer o desenvolvimento de nossas faculdades intelectuais nesse plano ético.

Em especial, merece menção a ética aristotélica, marcadamente teleológica, porque tudo aquilo que colabora para o alcance do fim do homem deve ser realizado, evitando-se, como consequência, tudo aquilo que o impede. No agir humano, pode existir um excesso, uma falta e um justo meio: por exemplo, numa circunstância de perigo iminente, é possível ser audacioso (excesso), covarde (falta) ou corajoso (justo meio). O justo meio consiste, portanto, em fazer o que se deve, quando se deve, nas 
circunstâncias em que se deve, às pessoas a quem se deve, pelo fim pelo qual se deve e como se deve (ARISTÓTELES, 2009, p. 50-55). Desse modo, a prudência, enquanto saber prático, volta-se à definição daquilo que é o bem aqui e agora (hic et nunc), na situação concreta, sopesando-se todas as circunstâncias.

Nesse sentir, formula-se proposta de educação lastreada em meios voltados a despertar para os valores éticos, de modo que as decisões judiciais sirvam de alavanca para a discussão dos valores subjacentes à jurisprudência, ponderando-se os valores éticos e jurídicos em conflito, na busca da prudência do ius, não para substituir a consciência individual ou para veicular qualquer certeza moral de conclusões abstratas. Afinal, "[...] o exercício prático do direito, ou seja, a perquirição do ideal de justiça em uma situação real não é distinto de um ato da prudência. Isto porque aquilo que é jurídico se manifesta na perspectiva da exegese de uma pessoa concreta em uma situação verdadeira [...]" (AMARAL, 2011, p. 301).

Portanto, a prudência é uma excelência ou habilidade que deve ser estimulada por meio de um processo pedagógico em que se privilegie o manejo teórico-prático das circunstâncias concretas, à luz de um trabalho de criação do direito a partir do texto normativo abstrato, visando àquilo que é concretamente justo.

\section{DESENVOLVENDO A RAZÃO PRÁTICA DO ALUNO COM O MÉTODO DO CASO}

Na mentalidade jurídica romana, a lei era feita para o homem (e não homem para a lei). Séculos mais tarde, com a ascensão de certas vertentes do positivismo jurídico, a relação inverteu-se, tendo sido proibida ao magistrado a criação hermenêutica de uma solução ao caso concreto, o que contribuiu para incutir no ensino do direito a ideia de que a formação discente deveria ser pautada na memorização do direito positivo, a partir de um fetichismo legal (SILVESTRE, 2013, p. 100).

A atividade hermenêutica hodierna, especialmente na seara da responsabilidade civil, demanda a superação da sedutora ideia de redução do direito aos textos normativos. Dessa forma, é preciso ter em mente que a construção da 
norma decisória, mediante atividade jurisdicional, não se resume a uma atividade meramente declaratória de um direito previamente dado, por mera exegese do texto legal. Nesse processo de interpretação e aplicação com caráter criativo, a partir de argumentação referenciada ao ordenamento jurídico, ressalta-se a importância da formulação de juízos de valor, constituindo atividade influenciada pelas experiências de vida e pela compreensão da realidade por parte do intérprete-aplicador.

Nesse diapasão, Humberto Ávila (2007, p. 30-34) ensina que as normas são sentidos construídos a partir da interpretação sistemática de textos normativos, de modo que a Ciência do Direito não pode ser reduzida à mera descrição do significado dos textos, os quais constituem o ponto de partida da interpretação. Cabe também evocar, a despeito da diferença de enfoque, a lição de Robert Alexy (2008, p. 553), após demonstrar a insuficiência da interpretação semântica e da interpretação genética: "o texto das disposições de direitos fundamentais vincula a argumentação por meio da criação de um ônus argumentativo a seu favor".

Atualmente, a dimensão fática, a par do direito legislado, afigura-se imprescindível na apreciação do caso concreto: o intérprete completa sua compreensão e, nesse processo, aparecem necessariamente valorações. Nesse sentir, a interpretação jurídica confere um papel destacado para a teoria dos valores. Entendida a interpretação jurídica como um saber prudencial, verifica-se também que cabe ao intérprete não apenas procurar elucidar o justo no caso concreto, mas também indicar os argumentos que embasam seu juízo de escolha por uma solução em detrimento de outras. Eis, portanto, a finalidade precípua do ensino jurídico: formar intérpretes-concretizadores, aptos a raciocinar sobre as categorias jurídicas, a construir o sentido e o alcance das normas e a conectar motivadamente a literalidade das disposições do direito legislado com os valores que fundam e inspiram a ordem jurídica justa possível.

Em busca de uma estratégia adequada para a formação jurídica nos moldes ora expostos, assume primordial utilidade o chamado método do caso, que se apresenta como um instrumento pedagógico eminentemente prudencial, isto é, uma metodologia que fomenta a ideia de direito como um saber prático, diferentemente do método expositivo tradicional. 
Christopher Colombus Langdell, responsável pela criação e aplicação do case method na Universidade de Harvard no século XIX, partia do pressuposto de que todos os precedentes da common law poderiam ser reduzidos, a partir de um exercício de indução, a um sistema perene de princípios gerais. Uma vez estabelecido esse rol, poderiam ser deduzidas as normas aplicáveis aos casos concretos, a partir de um diálogo socrático de perguntas e respostas em sala de aula (AMARAL, 2011, p. 250259). Ao professor não competia a tarefa de apresentar um conjunto de ideias para os alunos, mas sim estimular que eles se servissem desse conjunto como dados de problemas a serem resolvidos num caso concreto e, por intermédio desse caminho, descobrissem a regra de direito por indução (BARNES; CHRISTENSEN; HANSEN, 1987, p. 49-50).

As provocações do docente, no método do caso, são formuladas com vistas a estimular os estudantes a confrontar e a questionar as suas próprias certezas, constrangendo-os a analisar detidamente os fatos e a argumentação desenvolvida nos cases. Mediante atividade dialética e circular entre norma, fato, valor e caso precedente, o aluno desenvolve a percepção dos princípios reitores das situações jurídicas, para decantá-los em argumentos racionais aptos a serem compreendidos por quaisquer pessoas.

A relação entre o direito e o estudo do caso é bem antiga, pois os jurisconsultos romanos tinham pleno domínio da comunhão entre os casos práticos e o direito, consubstanciados nas responsa dos jurisprudentes (MOREIRA ALVES, 2014, p. 28-29). Ademais, o método medieval do debate se relaciona estreitamente com a dialética grega: nas disputas, que eram uma prática escolar generalizada, dois alunos, sob a orientação de um ou vários mestres, discutiam dialeticamente sobre uma questão previamente fixada. Desse modo, o método do caso não surge propriamente no mundo do common law, pois tem raízes já na dialética grega, no direito romano e no direito canônico medieval (TOLLER, 2006, p. 139, 146, 153 e 154).

Um dos possíveis itinerários na dinâmica da aula para esse trabalho de formação de prudência seria: a) leitura da decisão judicial; b) reconstrução dos fatos e circunstâncias relevantes; c) determinação dos principais problemas jurídicos em jogo; d) reconstrução das linhas argumentativas adotadas por cada uma das partes 
envolvidas; e) crítica dessas linhas argumentativas e da solução judicial; f) relação do caso com outros semelhantes, com a jurisprudência da mesma corte judicial e, eventualmente, com o direito comparado; e g) síntese das conclusões obtidas (FERNANDES, 2014, p. 237).

É possível identificar, de forma geral, as seguintes fases do método do caso: a) análise dos fatos e dos fundamentos jurídicos das decisões judiciais adotadas como paradigma; b) síntese do problema jurídico, com suas circunstâncias relevantes; c) análise das soluções possíveis; d) síntese motivada da decisão escolhida; e e) promulgação da decisão aplicável, permitindo-se controle social sobre a escolha (AMARAL, 2011, p. 305-307).

Enfim, o método do caso é capaz de fomentar no aluno não apenas uma formação pedagógico-jurídica aberta, reflexiva, crítica e criativa, mas também a principal virtude do jurista (a prudência), empregada na atividade interpretativa voltada à resolução de problemas jurídicos concretos.

Com essas considerações sobre delineamentos do método do caso, não se pretende a apresentação de um conceito exauriente sobre o método descrito, mas apenas um tratamento aberto que permita sua apresentação, levando-se em consideração que o seu conceito tem passado por transformações e adaptações, diante de novas ideias e de novos contextos acadêmicos. De todo modo, parece prevalecer a concepção de que se trata de instrumento didático que objetiva o ensino de habilidades voltadas para o desenvolvimento e a prática do raciocínio jurídico por meio da análise de decisões judiciais, com amparo no diálogo socrático (RAMOS; SCHORSCHER, 2009, p. 49 e 56-57).

\section{O MÉTODO DO CASO NO ENSINO DA RESPONSABILIDADE CIVIL}

Na perspectiva do pós-positivismo jurídico, o amplo reconhecimento da efetividade dos valores constitucionais veio exigir a releitura crítica dos institutos jurídicos tradicionais, mesmo à margem do direito legislado (SILVA, 2006, p. 333). Especificamente na seara da responsabilidade civil, está em curso uma profunda 
transformação de paradigmas, a inspirar a mudança de entendimentos jurídicos a despeito de modificações no texto das leis. Quanto a esse ponto, importa ressaltar que uma das características da realidade jurídica é a sua socialidade, ou seja, a sua qualidade de ser social, e que a essência do fenômeno jurídico é sempre e necessariamente valorativa e, portanto, cultural (REALE, 2004, p. 2 e 30-32),

Para adequar-se à complexidade da vida social e atender às exigências de proteção às vítimas de danos tidos por injustos, o sistema da culpa tem caminhado em direção ao sistema solidarista da reparação do dano. Ademais, no intuito de proteção à vítima, vem ocorrendo a flexibilização dos filtros tradicionais da reparação, como o elemento culpa e o nexo causal (SCHREIBER, 2009, p. 11-12) no sentido de salvaguardar o direito à indenização do prejudicado, quando presentes os requisitos jurídicos. Sem embargo, a ampliação demasiada do conceito de dano ressarcível mostra-se capaz de comprometer os próprios fundamentos da responsabilidade civil, fazendo recrudescer a litigiosidade e a vitimização no meio social, com estímulo à chamada blame culture, ao paternalismo do Estado e o aprofundamento da crise de morosidade enfrentada pelo Poder Judiciário.

Nesse sentir, Anderson Schreiber (2009, p.171-173) propõe a utilização da técnica de ponderação de valores para selecionar o interesse jurídico merecedor de tutela em casos complexos de responsabilidade civil. Diante da convicção de que nem todo dano pode ou deve ser reparado, a questão central do direito da responsabilidade civil passou a ser o estabelecimento de critérios que justifiquem a imputação a outrem de um prejuízo sofrido. Nesse mister, o jurista goza de pouco amparo, seja nos textos legais, que são bastante abertos e gerais, seja na produção doutrinária, envolvida em inúmeras polêmicas e carecedora de melhor sistematização, bem como maior harmonia com a jurisprudência.

A respeito do papel da jurisprudência e da doutrina na formação dos alunos, é certo que, de um modo geral, não há um critério para resolver o confronto entre valores de forma abstrata, considerando que o juízo de prudência depende das peculiaridades de cada situação de fato. Todavia, é possível afirmar que os precedentes judiciais auxiliam a resolução de casos futuros em que estejam presentes as mesmas condições de fato (MENDES et. al., 2007, p. 276). Ainda, os doutrinadores 
também podem cogitar tensões prováveis entre princípios constitucionais e emitir um posicionamento, independentemente dos casos concretos. Nessa esteira, Ana Paula de Barcellos (2006, p. 60-61) sustenta que a experiência contínua com a interpretação constitucional produz uma espécie de banco de dados, formado por situações problemáticas típicas, podendo ser realizado um raciocínio de natureza ponderativa que servirá para abalizar a resolução de demandas futuras.

Sem embargo, frequentemente o jurista enfrenta, na vida profissional, demandas cuja matéria de fundo ainda não foi suficientemente tratada na doutrina, ou cujas circunstâncias específicas diferem de esquemas gerais cogitados pelos doutrinadores. Sendo assim, para fazer a justiça no caso concreto, deve ser capaz de exercer sua razão prática, pensando o direito para construir a solução jurídica mais adequada.

Em esforço pragmático para ilustrar a possível condução de uma aula em que se aplique o método do caso em matéria de responsabilidade civil, passa-se a arrolar, de forma concatenada, indagações exemplificativas entendidas como aptas a estimular a reflexão dos alunos com o escopo de desenvolver sua razão prática para a melhor solução de problemas jurídicos.

Diante de um caso com potencial existência de direito a indenização por responsabilidade civil, pode-se questionar, inicialmente: Quais são os interesses em disputa? Ambos são juridicamente protegidos pelo ordenamento jurídico? Se sim, a conduta lesiva é vedada por norma jurídica específica? Se não, há, então, alguma regra legal de prevalência abstrata entre os interesses? Se não, como realizar a ponderação concreta entre os interesses em tensão, para determinar se o dano é ressarcível?

Quanto aos fundamentos utilizados para propor uma resposta à contenda, cabível inquirir: $O$ que é mais importante para decidir quanto à pretensão ressarcitória? Existe na tomada de posição algum viés apriorísitico de prevalência de interesses? É possível identificar motivação ideológica para a decisão? As condições econômicas e sociais dos envolvidos deve ser levada em consideração e, se sim, em que medida? A responsabilidade civil deve possuir uma função de desestímulo à repetição de condutas socialmente reprováveis? A responsabilidade civil deve 
promover a justiça distributiva, em favor dos mais pobres ou dos hipossuficientes em geral? É cabível a preocupação com a viabilidade econômica das atividades empresariais?

Quanto à matéria probatória, pode-se perquirir: Quais são as circunstâncias relevantes e irrelevantes no caso? Como a vítima se desincumbe do ônus de provar seu direito à reparação? O ônus da prova deveria ser invertido? Que modificação nas circunstâncias, por exemplo, seria suficiente para alterar a conclusão quanto à indenizabilidade do dano?

Sobre o quantum indenizatório, é pertinente indagar: Qual o grau de culpa do ofensor? Qual o grau de reprovabilidade de sua conduta? Qual o grau de contribuição causal do ofensor na cadeia de acontecimentos? Qual deve ser o critério para a fixação do valor da indenização, especialmente nos casos de danos extrapatrimoniais?

Já em relação à fundamentação de decisão do Poder Judiciário sobre o caso que seja apresentada aos alunos, pode-se questionar: Concorda-se com a solução para o conflito? A motivação foi suficiente para a resolução do caso? O debate em sala de aula foi mais ou menos esclarecedor que a fundamentação? Quais argumentos eventualmente não foram mencionados em sala de aula? O juiz forneceu "justificativas diversas e variadas" para a decisão, conforme o "dever de consistência" proposto pela hermenêutica democrática e pluralista de Peter Häberle (1997, p. 42)?

Esse conjunto de questões, trabalhados em sala de aula, de modo concatenado, operam o amadurecimento da dimensão prática do raciocínio jurídico, especialmente pela maiêutica, que permite ao professor administrar a progressiva incorporação de conhecimento acerca do caso sob exame e da legislação aplicável. A finalidade da aula não está na solução correta em si, mas no exercício da prudência necessária ao jurista.

A prudência mostra-se fundamental para a interpretação, a demandar que o hermeneuta busque, diante da abertura semântica dos textos normativos, a resolução que melhor realize a junção entre princípios de justiça e as circunstâncias do caso concreto. Estimula-se, assim, o desenvolvimento ético-moral para além do legalismo 
estrito, de molde a permitir a formação integral do discente como ser humano dotado de inteligência e disposição para a virtude (MELO, 2017, p. 80-84).

Por fim, como forma de avaliação dos alunos na atividade, que tem por escopo o verificar a ganho das habilidades específicas, propõe-se que o professor faça anotações sobre a participação dos discentes, possivelmente com o auxílio de um monitor, podendo atribuir escores de 1 a 3, conforme a intervenção tenha contribuído para o debate e demonstrado a preparação prévia para a discussão do caso, para, ao fim, atribuir um conceito a cada participante, comparando-se o seu desempenho com o dos demais. O feedback é necessário para compor o arco do aprendizado.

Em turmas com menor quantidade de alunos, propõe-se o controle qualitativo das participações, a fim de estimular os discentes a oferecer diferentes espécies de contribuições, como no padrão formulado por Amaral Júnior et al. (2016, online) para a avaliação em métodos participativos em geral:

\begin{abstract}
A participação dos alunos é apreciada nas aulas e monitorias com base em critérios quantitativos e qualitativos. Quanto a estes últimos, subdividem-se nas seguintes considerações: a) se os comentários do aluno são fundamentados nos textos sugeridos para leitura, b) se os comentários do aluno foram construídos de forma a indicar uma contribuição pessoal ao tema e c) se os comentários do aluno provocaram um debate sobre o tema ou contribuíram para a interação dos colegas naquele assunto, ou, ainda, para um fechamento, compilação ou estratificação das ideias já levantadas.
\end{abstract}

Do mesmo modo, considera-se produtivo que os alunos sejam instados a entregar uma breve dissertação sobre a atividade, na qual descrevam a solução que entendem justa para o caso estudado e fundamentem sua conclusão, à luz das provocações feitas pelo professor e das ponderações dos colegas.

\title{
6 EXEMPLO DE APLICAÇÃO DO MÉTODO DO CASO NA EDUCAÇÃO JURÍDICA: A DISCUSSÃO SOBRE A RESPONSABILIDADE DO ESTADO POR NOMEAÇÃO TARDIA EM CONCURSOS PÚBLICOS
}

Com o ânimo de conferir maior teor pragmático ao presente trabalho, passase a expor a possível forma de aplicação do método do caso a um problema jurídico 
real: a discussão sobre a responsabilidade do Estado nas situações em que aprovados em concurso público alegam danos decorrentes do atraso na data de suas investiduras, pois a nomeação é obtida apenas após a intervenção do Poder Judiciário ("nomeação tardia"). Serão apresentadas possíveis questões a serem sucessivamente lançadas pelo docente, acompanhadas de breve posicionamento teórico sobre os pontos suscitados. Ao final deste tópico, tratar-se-á da fundamentação do Recurso Extraordinário n. 724.347/DF, no qual o Supremo Tribunal Federal (STF) decidiu sobre a matéria em regime de repercussão geral.

Cumpre estimular a reflexão do discente sobre as relações entre a responsabilidade do Estado e a condução de concursos públicos que enseje atraso na nomeação de candidatos aprovados. Está-se diante da hipótese em que candidatos, mesmo após a regular aprovação no processo seletivo, restam impedidos de assumir o cargo público, em razão de interpretação da Administração Pública que vem a ser revertida judicialmente. Exsurge, assim, o questionamento sobre a reparação de danos materiais eventualmente sofridos por esses concursados entre a data em que deveria ter ocorrido a investidura e o momento em que se efetiva a nomeação por ordem judicial, período em que Ihes foi negado o exercício da função pública, com a percepção de vencimentos.

O método do caso permitirá ao discente desenvolver a razão prática sobre esse problema específico.

São duas demandas judiciais observadas entre um mesmo sujeito e a Administração Pública. O candidato, após lograr êxito no pedido de nomeação e posse no cargo público, por força de decisão judicial transitada em julgado, ingressa com uma segunda ação, na qual pleiteia indenização referente aos ganhos que deixou de auferir durante o período de atraso da investidura no cargo público.

Inicialmente, cabe identificar as partes em disputa: de um lado, um aprovado em concurso público que impugnou judicialmente uma decisão administrativa sobre o certame, vindo a obter provimento jurisdicional favorável transitado em julgado, no qual se reconhece o desacerto de ter sido obstada sua a investidura; de outro lado, a Administração Pública, que adotou uma interpretação durante a condução do concurso público, mas acabou por não lograr êxito na esfera judicial e foi instada pelo 
Poder Judiciário a dar posse ao candidato. De um lado, o interesse do concursado de não ser lesado por decisão administrativa equivocada; de outro lado, o interesse da Administração de exercer sua autonomia na busca do que entende ser juridicamente adequado no caso concreto, sem ser penalizada caso o Poder Judiciário venha a adotar posicionamento diverso.

Ambos os interesses são, em princípio, albergados pelo ordenamento jurídico. Não há regra legal específica que resolva a situação, seja para vedar a conduta da Administração, seja para fazer prevalecer a priori um interesse sobre o outro. É preciso, portanto, no caso concreto, escolher motivadamente o interesse jurídico merecedor de tutela.

Cabível indagar, em seguida: O nomeado tardiamente deve receber alguma compensação pelo atraso na investidura? Pode haver a percepção de valor monetário mesmo sem ter havido a prestação do serviço?

Sobre esse aspecto, pontua-se que o pedido de recebimento de remuneração passada seria improcedente, pois a percepção de vencimentos dependeria da contraprestação do serviço, sob pena de enriquecimento sem causa por parte do servidor. A problemática, contudo, é de complexidade mais acentuada. Não é possível asseverar que os candidatos pugnam pelo o recebimento de vencimentos retroativos: em verdade, buscam uma indenização pelo alegado dano material suportado no período em que foram impedidos de receber vencimentos por decisão da Administração que o Poder Judiciário veio a reputar errônea.

Avançando no debate, pode-se questionar: há ofensa à autonomia da Administração Pública caso venha a ser responsabilizada por interpretações jurídicas razoáveis, mas que não venham a ser acolhidas pelo Poder Judiciário? A solução deve ser diferente para os casos de dúvida ou polêmica quanto à medida adotada, em relação aos casos em que a posição da Administração era nitidamente equivocada? Em que medida a solução construída contribuirá para conferir segurança jurídica aos concursos públicos, tanto do ponto de vista dos candidatos, quanto do ponto de vista dos gestores públicos? 
Dito isso, é possível lançar a seguinte indagação, para a hipótese de se reconhecer o direito à indenização por nomeação tardia: há perda de uma chance ou lucro cessante?

É de se entender que a probabilidade de resultado útil, na hipótese de regular nomeação, é próxima à certeza, pois o candidato conseguiu ser aprovado para o preenchimento do cargo que havia escolhido como meta, sujeitando-se a cumprir todas as fases do concurso público para efetivar tal desiderato. A hipótese é bastante similar ao exemplo mais frequente de lucros cessantes: aquele do motorista de táxi que tem o veículo abalroado e deixa de trabalhar durante o conserto do carro na oficina mecânica. Situação bastante diferente, por exemplo, seria aquela em que o concursando deixa de participar da última fase de um concurso por atraso no voo que o transportava. Nesta última hipótese, apenas poderia haver responsabilização, a depender das circunstâncias, por perda de uma chance: não estaria configuraria lucro cessante, pois não se poderia demonstrar patentemente a probabilidade robusta de que o candidato teria desempenho suficiente à aprovação, para depois, investido no cargo, receber os devidos vencimentos (CAPISTRANO, 2010, online).

Prosseguindo na análise, passa-se à apreciação do quantum da indenização por nomeação tardia, se reconhecida. Compreende-se que deve corresponder, em princípio, aos vencimentos e demais vantagens inerentes ao cargo - importância que o cidadão lesado teria percebido caso nomeado oportunamente, pelo princípio da restitutio in integrum. Nesse sentido já se expressou o Superior Tribunal de Justiça (STJ), no Recurso Especial n. 506.808/MG:

\footnotetext{
Em matéria de responsabilidade civil, vigora o princípio da restitutio in integrum, segundo o qual a indenização deve alcançar à vítima tudo aquilo que teria obtido não fosse o evento danoso. É a regra geral insculpida no art. 944, caput, do Código Civil: "A indenização mede-se pela extensão do dano". Deve o recorrente receber, nesses moldes, indenização no valor correspondente ao dos vencimentos e demais vantagens relativas ao cargo que teria auferido não fosse o ilegítimo impedimento à sua posse, no período compreendido entre o dia em que deveria ter ocorrido a investidura (24.10.1994) e aquele em que efetivamente ocorreu (24.12.1997).
}

Por outro lado, não se pode olvidar que o fundamento para a concessão do total de vencimentos e vantagens ao prejudicado consiste na ideia de reparação ao 
dano injusto experimentado. A extensão do ressarcimento devido diminui caso o concursado tenha auferido renda proveniente de trabalho durante o período em que deveria estar no exercício do cargo público. Nessa hipótese, entende-se que o concursado demandante tem direito somente à diferença entre os valores que teria recebido se nomeado oportunamente e o montante obtido em decorrência da atividade laboral que tenha desempenhado.

Encerrada a primeira fase de debates, propõe-se que os discentes tenham contato com o inteiro teor do acórdão do já mencionado Recurso Extraordinário n. 724.347/DF. Preferencialmente, a segunda etapa de debates será realizada na aula seguinte, para que os alunos possam estudar a fundamentação de forma mais detida.

Nessa segunda fase de debates, busca-se identificar qual foi a resposta construída pelo STF e qual a sua fundamentação.

Convém evidenciar para os discentes o contexto histórico da decisão, considerando que o problema encontrava tratamentos díspares na jurisprudência, em afronta à segurança jurídica.

Em fevereiro de 2011, a Corte Especial do STJ, ao julgar os Embargos de Divergência em Recurso Especial n. 825.037/DF, firmou o entendimento de que, em casos de nomeação por decisão judicial, não assiste ao concursado o direito de receber, pura e simplesmente, o valor dos vencimentos que poderia ter auferido até o advento da nomeação determinada judicialmente; reconheceu-se, todavia, o direito a indenização por perda de chance, que, naquele caso concreto, corresponderia à diferença entre os vencimentos do cargo e o valor que, no período da demora, o concursado havia recebido no desempenho de atividade contratual.

Poucos meses depois, a mesma Corte Especial do STJ, no julgamento dos Embargos de Divergência em Recurso Especial n.117.974/RS, modificou seu posicionamento, no sentido de que o candidato cuja nomeação tardia tenha ocorrido por força de decisão judicial não tem direito a indenização pelo tempo em que aguardou a solução definitiva pelo Judiciário: "Considera-se que, se a nomeação foi decorrente de sentença judicial, o retardamento não configura preterição ou ato ilegítimo da Administração Pública a justificar uma contrapartida indenizatória". 
Diante do conflito, o STF foi instado a decidir a matéria em sede de repercussão geral, no âmbito do já citado Recurso Extraordinário n. 724.347/DF. Trata-se de Recurso Extraordinário interposto pela União contra acórdão proferido pelo Tribunal Regional Federal da 1ำ Região, que havia reconhecido direito de indenização a dez auditores-fiscais da Receita Federal, correspondente à remuneração do cargo no período de 13.06.1995 (data a partir da qual alegam terem sido preteridos por outros candidatos aprovados) a 25.07.1997 (data da efetiva nomeação dos recorridos), descontando-se eventuais rendimentos recebidos no período, com juros e correção.

O julgamento no STF iniciou-se em 23 de outubro de 2014, tendo sido interrompido por pedido de vista e retomado em 26 de fevereiro de 2015. O Min. Marco Aurélio, relator, entendeu cabível a responsabilidade objetiva do Estado, com fundamento na teoria do risco administrativo, mas prevaleceu a divergência inaugurada pelo Min. Luís Roberto Barroso, pela inviabilidade da indenização, salvo em casos de arbitrariedade flagrante. $O$ acórdão contém votos escritos e a transcrição de debates entre os Ministros.

Após coletar a posição de alguns alunos sobre a solução encontrada pelo STF, o professor poderá mostrar que o Min. Marco Aurélio, relator, considerou a nomeação tardia como fato gerador de responsabilidade objetiva do Estado. Seu posicionamento viria a ser perfilhado pelo Min. Luiz Fux (p. 30-32):

[O] Professor Celso Antônio Bandeira diz assim: o Estado de Direito lesou, tem que reparar. Agora, eu acho que faz parte do múnus público dos advogados do poder público resistir, correndo o risco de ter que reconhecer um direito com eficácia retro-operante, porque, se deram posse, é porque eles já tinham o direito à posse. [...] De que vive o homem? Vive de esperança. Esse homem fez um concurso, e a esperança é um direito legítimo de qualquer cidadão. [...] numa Constituição pós-positivista como a nossa, humanizada como a nossa, tratar com indiferença isso realmente não me satisfaz em termos de justiça.

Entretanto, esse posicionamento do relator não prevaleceu. $O$ voto divergente vencedor, do Min. Luís Roberto Barroso (p. 12-18), assenta-se, inicialmente, no argumento inadequado da impossibilidade de percepção de vencimentos sem prestação de serviços, conforme se sustentou acima. 
Adiante, é possível verificar que o voto realiza uma ponderação ${ }^{1}$ entre os interesses em jogo, para concluir, segundo a razão prática, que a indenização será cabível apenas em casos de arbitrariedade flagrante:

13. No entanto, é preciso ressalvar situações de arbitrariedade qualificada, tal como faz a jurisprudência do Supremo Tribunal Federal. A simples existência de um litígio judicial sobre concurso público é fato normal na vida de uma sociedade com instituições, e a defesa judicial pelo Estado de um ponto de vista minimamente razoável, dentro das regras do jogo, não gera dano indenizável. No entanto, em situações de patente arbitrariedade, descumprimento de ordens judiciais, litigância meramente procrastinatória, má-fé e outras manifestações de desprezo ou mau uso das instituições, ocorrem fatos extraordinários que exigem reparação adequada (p. 5-6)

Veja-se que, especificamente para pleitos indenizatórios envolvendo nomeação tardia, foi efetivada uma construção hermenêutica que exige dolo ou culpa grave para configurar-se a responsabilidade do Estado, afastando-se do regime geral de responsabilidade objetiva previsto na cláusula geral do art. $37, \S 6^{\circ}$, do texto constitucional. $^{2}$

Entende-se que essa ponderação de interesses jurídicos realizada no voto escrito do Min. Luís Roberto Barroso apresenta-se como a técnica adequada para a resolução do problema, conforme juízo de razoabilidade ou prudência do órgão julgador. Todavia, acredita-se que a fundamentação teria sido mais clara se mencionasse expressamente que se estava a realizar uma ponderação dos interesses jurídicos em disputa.

Assim, em sede de repercussão geral, o STF estabeleceu, no julgado em estudo, diretriz para a generalidade dos casos de pedido de indenização por nomeação tardia, por meio da seguinte tese: "na hipótese de posse em cargo público determinada por decisão judicial, o servidor não faz jus a indenização, sob fundamento

\footnotetext{
${ }^{1}$ Utiliza-se, no presente estudo, a ideia de ponderação de interesses jurídicos no contexto de prudência ou razoabilidade na razão prática, como proposto por Zagrebelsky.

${ }^{2}$ No voto do Min. Dias Toffoli (p. 19-23), sustentou-se que a responsabilidade objetiva prevista no aludido dispositivo alcança apenas "[...] danos causados a terceiros na prestação de serviços públicos, não tendo aplicação às hipóteses de realização de concursos e de não nomeação [...]".
} 
de que deveria ter sido investido em momento anterior, salvo situação de arbitrariedade flagrante". 3

Reputa-se profícuo que os discentes sejam instados a se manifestar sobre a concordância ou discordância em relação a essa solução, com a devida justificação. De modo socrático, o professor pode confrontar as posições dos discentes, como estímulo ao aprimoramento argumentativo.

Nesse momento, propõe-se que sejam introduzidos os conceitos de coerência e integridade como parâmetros de aferição da correção de decisões judiciais, a fim de que seja enriquecida a capacidade dos discentes de realizar uma crítica fundamentada.

No enfrentamento das demandas envolvendo responsabilidade civil, cabe à função jurisdicional do Estado a preservação do ordenamento jurídico, conferindo-Ihe, para cumprir a conformidade do texto constitucional, coerência e integridade. Aliás, diante de sua relevância, a exigência de coerência e integridade da jurisprudência dos tribunais passou a ser expressamente estabelecida no artigo 926 do novo Código de Processo Civil. ${ }^{4}$

Os termos "coerência" e "integridade" remetem à terminologia de Ronald Dworkin, cuja teoria da integridade permite compreender que não se pode confundir a visão pragmática, isto é, aquela que se volta ao resultado, com a visão jurídica, que tem por finalidade a coerência em sentido amplo das decisões judiciais:

\begin{abstract}
O pragmatismo exige que os juízes pensem de modo instrumental sobre as melhores regras para o futuro [...] O direito como integridade é diferente: é tanto o produto da interpretação abrangente da prática jurídica quanto sua fonte de inspiração. O programa que apresenta aos juízes que decidem casos difíceis é essencialmente, não apenas contingentemente, interpretativo; o direito como integridade pede-Ihes que continuem interpretando o mesmo material que ele próprio afirma ter interpretado com sucesso (DWORKIN, 1999, p. 273).
\end{abstract}

\footnotetext{
${ }^{3}$ Acerca do quantum indenizatório, verifica-se que o ponto não foi decidido pelo STF no acórdão em estudo, por não ter sido objeto do recurso, mas foi mencionado como obiter dictum (p. 36), no mesmo sentido do que se defendeu anteriormente: o valor deve corresponder ao total da remuneração não recebida no cargo público, descontando-se o valor eventualmente recebido em outra atividade laboral exercida no mesmo período.

4 "Art. 926. Os tribunais devem uniformizar sua jurisprudência e mantê-la estável, íntegra e coerente."
} 
Exige-se do magistrado uma atuação pautada "em princípios, e não por fé". Segundo a doutrina da responsabilidade, "os homens integram suas intuições e subordinem algumas delas, quando necessário, a essa responsabilidade", ao pressupor uma "coerência articulada, assim como decisões de acordo com um programa que possa tornar-se público e ser seguido enquanto não for modificado", características fundamentais de qualquer concepção de justiça (DWORKIN, 2002, p. 252).

Para Dworkin (1999, p. 264), "a integridade exige que as normas públicas da comunidade sejam criadas e vistas, na medida do possível, de modo a expressar um sistema único e coerente de justiça e equidade na correta proporção".

A coerência assegura o respeito à igualdade, de modo que os diversos casos terão a igual consideração por parte do juiz, restando assegurada a integridade do direito a partir da força normativa da Constituição. Já a integridade exige que os juízes construam seus argumentos de forma integrada ao conjunto do direito, constituindo uma garantia contra arbitrariedades interpretativas.

É certo, ainda, que, para Dworkin (1999, p. 264-265), a coerência e integridade não se satisfazem com a simples estabilidade nas decisões judiciais a respeito de uma mesma questão jurídica, pois a integridade incentiva um juiz a ser mais abrangente e imaginativo em sua busca de coerência com o princípio fundamental, como no exemplo sobre responsabilidade civil dos advogados:

\begin{abstract}
Durante algum tempo, os juízes ingleses declararam que embora os membros de outras profissões fossem responsáveis por danos causados por sua negligência, os advogados eram imunes a tal responsabilidade. Entendida em sentido estrito, a coerência teria exigi do a continuidade dessa exceção, mas a integridade condena o tratamento especial dispensado aos advogados, a menos que este possa ser justificado em princípio - o que parece improvável. A Câmara dos Lordes atualmente reduziu essa isenção: ao fazê-lo, preferiu a integridade à coerência estrita.
\end{abstract}

A integridade em Dworkin se contrapõe ao voluntarismo do juiz, igualmente autor e crítico. Ao interpretar uma tradição, o juiz introduz um acréscimo que será interpretado pelos juízes futuros, numa espécie de romance em cadeia (chain novel), em que "cada romancista da cadeia interpreta os capítulos que recebeu para escrever um novo capítulo, que é então acrescentado ao que recebe o romancista seguinte, e 
assim por diante" (1999, p. 276). Nesse processo, o juiz, assim como o romancista, deve criar a melhor interpretação possível como se fosse a obra de um único autor. Tratando-se de uma continuidade e não de um novo começo, não pode a decisão basear-se na discricionariedade do julgador.

Entende-se que a observância da tese de repercussão geral do Recurso Extraordinário n. 724.347/DF pelos demais órgãos julgadores garantirá coerência na jurisprudência, nos termos propostos por Dworkin, pois casos com a mesma e única questão jurídica terão a mesma solução, promovendo-se o princípio da igualdade. Ainda, nota-se que o STF não determinou a mesma solução para todos os casos de nomeação tardia, tendo excepcionado as hipóteses de arbitrariedade flagrante, em consonância com a doutrina do direito como integridade, na busca de um sistema único e coerente de justiça e equidade, na correta proporção.

\section{CONCLUSÃO}

Em casos concretos nos quais se discute responsabilidade civil, o texto normativo apresenta contribuição acentuadamente incipiente, considerando que as disposições legais são sucintas e deixam amplíssima margem de decisão para a concretização do direito à indenização. Portanto, nesse campo, percebe-se com ainda maior nitidez a imprescindibilidade da superação da sedutora ideia de redução do direito aos textos normativos.

No processo de interpretação e aplicação com caráter criativo, a partir de argumentação referenciada ao ordenamento jurídico, ressalta-se a importância da formulação de juízos de valor, constituindo atividade influenciada pelas experiências de vida e pela compreensão da realidade por parte do intérprete-aplicador. Ainda, a existência de vários métodos de interpretação deve ser vista não como um defeito teórico, mas como um dever da nossa cultura jurídica, de modo que a "razoabilidade" ou "prudência" deixa de se configurar como um elemento subjetivo do jurista para se objetivar no próprio ordenamento jurídico. 
Entendida a interpretação jurídica como um saber prudencial, verifica-se também que cabe ao intérprete não apenas procurar elucidar o justo alcançável no caso concreto, mas também indicar os argumentos que embasam seu juízo de escolha por uma solução e não pelas outras. A finalidade precípua do ensino jurídico é formar intérpretes-concretizadores, aptos a raciocinar sobre as categorias jurídicas, a construir o sentido e o alcance das normas e a conectar motivadamente a literalidade das disposições do direito legislado com os valores que fundam e inspiram a ordem jurídica justa possível.

O método do caso prepara a capacidade reflexiva para percepção dos valores e interesses envolvidos no caso submetido a análise, mais necessária em face da insuficiência do direito legislado e da doutrina. Estimula-se, assim, o desenvolvimento ético-moral para além do legalismo estrito, de molde a permitir a formação integral do discente como ser humano dotado de inteligência e disposição para a virtude.

Em esforço pragmático para ilustrar a possível condução de uma aula em que se aplique o método do caso em matéria de responsabilidade civil, foram arroladas neste artigo, de forma concatenada, indagações exemplificativas e gerais entendidas como aptas a estimular a reflexão do discente com o escopo de desenvolver sua razão prática para a prudente solução de problemas jurídicos. Ainda, elaborou-se roteiro ilustrativo de aula a respeito de um problema jurídico real: a possível responsabilidade do Estado por nomeação tardia em concursos públicos, tema enfrentado pelo STF no julgamento do Recurso Extraordinário n. 724.347/DF, em regime de repercussão geral.

\section{REFERÊNCIAS}

ALEXY, Robert. Teoria dos direitos fundamentais. São Paulo: Malheiros, 2008.

AMARAL, Antônio Carlos Rodrigues do. Ensino jurídico e método do caso: ética, jurisprudência, direitos e garantias fundamentais. Porto Alegre: Lex Magister, 2011.

AMARAL JUNIOR, Alberto do et al. O modelo de ensino participativo no Direito Internacional: relato de uma experiência. Rev. direito GV, São Paulo, v. 12, n. 3, p. 632-647, dez. 2016.2 Disponível em: $<$ http://www.scielo.br/scielo.php?script=sci_arttext\&pid=S1808- 
$24322016000300632 \& \mid \mathrm{ng}=\mathrm{pt \& nrm}=\mathrm{iso}>$.

Acesso

em: 19 dez. 2017. http://dx.doi.org/10.1590/2317-6172201626.

AQUINO, Tomás de. A prudência: a virtude da decisão certa. Tradução de Jean Lauand. São Paulo: Martins Fontes, 2005.

ARISTÓTELES. Ética a Nicômaco. Tradução do grego de António de Castro Caeiro. São Paulo: Atlas, 2009.

ÁVILA, Humberto. Teoria dos princípios: da definição à aplicação dos princípios jurídicos. 7. ed. ampl. e atual. São Paulo: Malheiros, 2007.

BARCELLOS, Ana Paula de. Alguns parâmetros normativos para a ponderação constitucional. In: BARROSO, Luís Roberto (Org.). A nova interpretação constitucional. 2. ed. rev. e atual. Rio de Janeiro: Renovar, 2006.

BARNES, Louis B.; CHRISTENSEN, C. Roland; HANSEN, Abby J. Teaching and the case method. 3. ed. Boston: Harvard Business School, 1987.

BRASIL. Código de Processo Civil (2015). Disponível em: <https://www.planalto.gov.br/ccivil_03/_ato2015-2018/2015/lei//13105.htm >. Acesso em: 21 maio 2017.

Constituição da República Federativa do Brasil (1988). Disponível em: < https://www.planalto.gov.br/ccivil_03/constituicao/constituicaocompilado.htm>. Acesso em: 21 maio 2017.

Superior Tribunal de Justiça. Embargos de Divergência em Recurso Especial n. 825.037/DF. Relator: Min. Eliana Calmon. Corte Especial. Brasília, 1ํo de fevereiro de 2011.

Recurso Especial n. 506.808/MG. Relator: Ministro Teori Albino Zavascki. Primeira Turma. Brasília, 29 de junho de 2006.

1.117.974/RS. Relator p/ Acórdão: Min. Teori Albino Zavascki. Corte Especial. Brasília, 21 de setembro de 2011.

Supremo Tribunal Federal. Recurso Extraordinário n. 724.347/DF. Relator: Ministro Marco Aurélio. Relator p/ acórdão: Ministro Roberto Barroso. Tribunal Pleno. Repercussão geral. Brasília, 26 de fevereiro de 2015.

CAPISTRANO, Márcio Anderson Silveira. Responsabilidade do Estado por nomeação tardia de aprovado em concurso público: análise crítica da jurisprudência brasileira. In: XIX Encontro Nacional do Conpedi. 2010, Fortaleza. Anais eletrônicos... Fortaleza, Conselho Nacional de Pesquisa e Pós-Graduação em Direito. 2010. Disponível em: 
https://s3.amazonaws.com/conpedi2/anteriores/XIX+Encontro+Nacional+-+UFCFortaleza+(09\%2C+10\%2C+11+e+12+de+junho+de+2010).pdf $>$. Acesso em: 19 dez. 2017.

DWORKIN, Ronald. Levando os direitos a sério. Trad. Nelson Boeira. São Paulo: Martins Fontes, 2002. Fontes, 1999.

O império do direito. Trad. Jefferson Luiz Camargo. São Paulo: Martins

FERNANDES, André Gonçalves. Ensino do Direito e Filosofia: A prudência e a hermenêutica jurídicas, apreendidas com o estudo do caso da identidade crítica, como fundamentos da formação para a justiça como prática social. 2014. 377 f. Tese (Doutorado) - Curso de Filosofia e História da Educação, Universidade Estadual de Campinas, Campinas, 2014.

HÄBERLE, Peter. Hermenêutica constitucional: a sociedade aberta dos intérpretes da Constituição: Contribuição para a interpretação pluralista e "procedimental" da Constituição. Trad. Gilmar Ferreira Mendes. Porto Alegre: Sergio Antonio Fabris Editor, 1997.

MELO, Rafael Castro Veras. A formação do jurista na prudência como desafio do ensino jurídico. 2017. 96 f. Dissertação (Mestrado Acadêmico) - Programa de Mestrado em Direito Constitucional, Universidade de Fortaleza, Fortaleza, 2017.

MOREIRA ALVES, José Carlos. Direito romano. 16. ed. Rio de Janeiro: Forense, 2014.

MÜLLER, Friedrich. Teoria estruturante do Direito. Tradução de Peter Naumann, Eurides Avance de Douza. 2. ed. São Paulo: Revista dos Tribunais, 2009.

RAMOS, Luciana de Oliveira; SCHORSCHER, Vivian Cristina. Método do Caso. In: GHIRARDI, José Garcez et al (Org.). Métodos de ensino em Direito: Conceitos para um debate. São Paulo: Saraiva, 2009. p. 49-60.

REALE, Miguel. Lições preliminares de direito. 27. ed. 4. tir. São Paulo: Saraiva, 2004.

SCHREIBER, Anderson. Novos paradigmas da responsabilidade civil. 2. ed. São Paulo: Atlas, 2009.

SILVA, Alexandre Garrido da. Direito, correção normativa e institucionalização da justiça. Revista de Direito do Estado, São Paulo, ano 1, n. 1, p. 331-346, jan./mar. 2006.

SILVESTRE, Ana Carolina de Faria. Os desafios à educação jurídica em tempos de "pós-racionalidade". In: GHIRARDI, José Garcez (Org.); FEFERBAUM, Marina (Org.). Ensino do direito em debate: reflexões a partir do $1^{\circ}$ Seminário Ensino Jurídico e 
Formação Docente. São Paulo: Direito GV, 2013. p. 95-106.

TOLLER, Fernando M. Origens históricas da educação jurídica com o método do caso. Quaestio luris, Rio de Janeiro, v. 02, n. 01, p.134-165, 2006.

ZAGREBELSKY, Gustavo. El derecho dúctil. Ley, derechos y justicia. Trad. Marina Garcón. Madrid: Trotta, 1995. 